\title{
Brecha digital educativa. Cuando el territorio es importante
}

\author{
Olga Martínez López ${ }^{1}$
}

\section{Introducción}

\author{
La Organización para la Cooperación y el Desarrollo Económicos (OCDE) define la brecha digital como
}

la distancia existente entre individuos, áreas residenciales, áreas de negocios y geográficas en los diferentes niveles socio-económicos en relación a sus oportunidades para acceder a las nuevas tecnologías de la información y la comunicación, así como al uso de Internet, lo que acaba reflejando diferencias tanto entre países como dentro de los mismos (OECD, 2001).

La brecha digital es, ante todo, expresión de la desigualdad en el uso y acceso de las nuevas Tecnologías de la Información y la Comunicación (TIC), y como desigualdad es generadora de procesos de exclusión social. Las causas que acompañan a su aparición son múltiples, desde la falta de las competencias y destrezas necesarias para el uso de las TIC, hasta la imposibilidad de acceder a los recursos electrónicos y de conexión necesarios, debido a bajos umbrales de renta. Podemos hablar de "Brechas digitales", debido a que se configuran como procesos multidimensionales que incluyen barreras de diferentes tipos (Cabero, 2004).

El objetivo de este artículo es introducir en el debate actual la importancia del territorio en los procesos de desigualdad social y educativa, producidos por la brecha digital, al mismo tiempo que se observan los problemas derivados de la situación de emergencia sociosanitaria en el ámbito educativo, y que se relacionan directamente con el desarrollo de la educación virtual o a distancia establecida en este periodo.

\section{Brecha digital y territorio}

Las adaptaciones del curso escolar a la actual situación de emergencia sociosanitaria, se han basado fundamentalmente en la educación virtual, es decir, en la continuidad del curso escolar a través de internet, lo que se traduce en la necesidad de las familias de disponer de los elementos electrónicos y de conectividad adecuados para su seguimiento, y de las destrezas y competencias necesarias para su uso. Esto se traduce en que, para que los niños, niñas y adolescentes, puedan continuar con el curso escolar en las actuales condiciones, es necesario no encontrarse afectados por esta brecha digital motivada por factores socioeconómicos y/o competenciales.

En la Comunidad de Madrid, según nos indican los datos de la Encuesta sobre Equipamiento y Uso de Tecnologías de Información y Comunicación en los hogares, realizada por el INE en 2019, encontramos que el 1,3\% de los hogares en los que reside al menos una persona menor de 16 años no dispone de conexión a internet, y el 2,8\% no dispone de ordenador.

Aunque el porcentaje en sí mismo no parece alarmante, encontramos que existen más de 600.000 hogares en la Comunidad de Madrid que se enfrentan a este problema. Lo que no nos presenta esta encuesta es la distribución de estos hogares a nivel territorial dentro de las propias Comunidades Autónomas, pero parece evidente que las zonas con un mayor índice de vulnerabilidad son las más afectadas.

En 2018, se elaboró el índice de vulnerabilidad para barrios y distritos de la ciudad de Madrid, en el que la vulnerabilidad se define como

\footnotetext{
Licenciada en Sociología, Máster en Formación del Profesorado en la especialidad de Formación y Orientación Laboral. España.

E-mail: olgamartnezlopez@gmail.com
} 
la potencialidad de que la población de un determinado espacio urbano concreto sea afectada por alguna situación adversa. Es decir: se dan unas determinadas condiciones de riesgo, fragilidad y desventaja que harían posible la entrada en una situación crítica de desfavorecimiento, entendido éste como la aparición de una situación de exclusión que puede llegar a consolidarse (Ayuntamiento de Madrid. Área de Coordinación Territorial y Cooperación Público Social 2018).

Este índice, que contempla el nivel de renta de los hogares, así como la tasa de desempleo o la percepción de Renta Mínima de Inserción, entre otras, nos permite obtener una visión del desequilibrio existente en la ciudad de Madrid. Los distritos del sureste madrileño son los que presentan un índice de vulnerabilidad mayor, lo que nos indica que en la actual crisis sanitaria y social, se ha producido un impacto superior al del resto de la ciudad.

El Ayuntamiento de Madrid acaba de publicar un informe denominado "Informe del Estudio sobre el impacto de la situación de confinamiento en la población de la ciudad de Madrid, tras la declaración del estado de alarma por la pandemia COVID-19. Impacto económico y laboral sobre los hogares". En este documento nos presentan los datos relativos al impacto de la pandemia del COVID-19 relativos a los ingresos de los hogares, y también los que se refieren a la presión asistencial en los servicios sociales.

Son los hogares con rentas más bajas los que han sufrido una mayor caída de sus ingresos, unido a que esta caída afecta en mayor medida a aquellos que tienen personas menores a cargo, con especial incidencia en los hogares monoparentales. En el ámbito de la presión asistencial en los servicios sociales, el porcentaje de aquellos que declaran que necesitaran algún tipo de ayuda dobla al del año anterior.

Teniendo en cuenta que el factor de la renta media de los hogares se relaciona directamente con la posibilidad de tener los medios necesarios en cuanto a equipamiento electrónico y acceso a internet, son las familias de los distritos con mayor índice de vulnerabilidad las que se ven más afectadas por la brecha digital, y por tanto, los niños, niñas y adolescentes, ven mermado su derecho a la educación, ya que no pueden acceder a la misma en igualdad de condiciones.

Brecha digital que se traduce en desigualdad educativa y social. En un contexto de vulnerabilidad, las familias no disponen de los recursos electrónicos suficientes ni de un acceso óptimo a internet. Debemos contemplar también, que en el contexto indicado, la brecha digital aparece también como la falta de competencias o destrezas necesarias para el uso de las TIC, lo que suele relacionarse con un bajo capital educativo en las familias.

Como indicábamos anteriormente, esta desigualdad se concentra territorialmente, motivando procesos de reproducción social, en la que zonas con altos índices de abandono escolar temprano, suman esta nueva forma de exclusión social.

En la actualidad los instrumentos metodológicos para analizar la relación entre brecha digital y desigualdad educativa no contemplan un escenario de pandemia global. Un escenario que ha modificado de una manera sin precedentes, las formas en las que se desarrolla la actividad educativa.

La mayor parte de los datos sobre la situación actual proceden de las redes informales surgidas ante esta crisis, y de las entidades dedicadas al trabajo con la infancia. Sabemos de la imposibilidad de muchas familias para enfrentar este nuevo periodo educativo, como sabemos las dificultades que un gran segmento de la población está teniendo para cubrir sus necesidades básicas.

Save The Children ha publicado recientemente el informe "A tu lado. Lo que nos cuentan las familias", dirigido fundamentalmente a investigar la situación de niños y niñas en situación de vulnerabilidad, en el que la brecha educativa aparece como uno de los primeros factores de fomento de la desigualdad educativa, que tiene un alto impacto en el aumento de la marginalidad y el aislamiento.

Pero si hablamos de las condiciones en las que se ha llevado el curso escolar, en el escenario de suspensión de clases presenciales, no podemos obviar las dificultades inherentes al propio proceso.

En lo relativo a la formación del profesorado, las competencias digitales para la docencia suponen, en parte, una redefinición de los roles tradicionales. Pese a la importancia que revisten, no se ha logrado una integración adecuada en los procesos de formación del profesorado.

Al mismo tiempo, las administraciones educativas no han realizado la inversión necesaria para generar entornos educativos virtuales adecuados, con la calidad suficiente para el curso escolar pueda desarrollarse de manera telemática. Ciertamente el escenario de pandemia global no ha sido contemplado en ningún sector, y ha obligado a improvisar o a desarrollar procesos que se encontraban en fase inicial, lo que ha demostrado la importancia de que las administraciones públicas, con especial énfasis en la educativa, deben adaptarse cada vez más a las herramientas y procesos que ofrecen las Tecnologías de la Información y la Comunicación.

Esos entornos virtuales deben ir acompañados de metodologías específicas que apoyen y faciliten los procesos educativos, y permitan un desarrollo curricular efectivo. Entendiendo este último de forma amplia, con gran importancia de los contenidos transversales, como la educación en valores o el desarrollo de la inteligencia emocional. Pero nuestro sistema educativo no ha explorado este ámbito de manera suficiente, lo que se está reflejando en las dificultades para el desarrollo de este periodo lectivo. 


\section{Brecha digital, inclusión educativa y medidas de atención a la diversidad}

La inclusión educativa es una de las máximas de nuestro sistema educativo actual, y siguiendo el criterio de la UNESCO (2005), la inclusión se relaciona con el acceso, la participación y los logros de todos los alumnos y alumnas, con especial énfasis en aquellos que están en riesgo de ser excluidos o marginados.

Si sumamos a este concepto la inclusión digital, entendida como el proceso necesario para garantizar el acceso de todas las personas a las Tecnologías de la Información y la Comunicación, encontramos un escenario en el que los sistemas educativos deben, por un lado, dotar al alumnado de las competencias y destrezas necesarias para este acceso y uso de las mismas, y por otro, los poderes públicos deben llevar a cabo las políticas necesarias para que las poblaciones dispongan de los recursos necesarios para este acceso.

El escenario actual nos muestra que la inclusión digital en el ámbito educativo es un proceso inacabado, y que afecta de manera especial a colectivos en riesgo de exclusión social.

Las medidas de atención a la diversidad son uno de los elementos que persiguen la consecución del principio de inclusión educativa. En el caso de la Comunidad de Madrid, estas medidas atienden a 3 elementos, por un lado, las dirigidas a alumnado con altas capacidades, por otro las dirigidas al alumnado con necesidades educativas especiales y, por último, alumnado de incorporación tardía al sistema educativo.

La Comunidad de Madrid, en su sitio web, nos presenta las medidas dirigidas al alumnado con necesidades educativas especiales con el siguiente texto:

La Administración educativa tiene la responsabilidad de garantizar el derecho a la educación a toda la población escolar, en situación personal, poniendo en marcha medidas precisas para que cualquier alumno ejerza dicho derecho.

Surge entonces la pregunta ¿es la brecha digital posible objeto de estas medidas? Si el objetivo fundamental de las mismas es garantizar el derecho a la educación, ¿son suficientes las adaptaciones curriculares? ¿Se atiende a factores socioeconómicos y familiares a la hora de atender a este alumnado? ¿Permite la escuela que orígenes socioeconómicos diversos tengan las mismas oportunidades?

Nos encontramos ante un escenario desconocido, una situación que está poniendo al límite a nuestros servicios públicos, incluido nuestro sistema educativo. En un breve periodo de tiempo ha sido necesario adaptar la escuela a un entorno virtual poco explorado por nuestros centros de enseñanza, al mismo tiempo que se realiza un seguimiento del alumnado para garantizar su derecho a la educación.

La urgencia, y la incertidumbre ante el comienzo del próximo curso escolar, nos impelen a tomar medidas que garanticen que todos los niños y niñas van a poder continuar su formación en las mejores condiciones, pero sobre todo, en igualdad de condiciones.

En conclusión, ante un escenario desconocido como el actual, se ha puesto de manifiesto la necesidad de que nuestro sistema educativo sea más flexible, y disponga de una mayor capacidad para trabajar en entornos virtuales. $\mathrm{Al}$ mismo tiempo debe abordar en profundidad las medidas necesarias para asegurar la igualdad de oportunidades a todos los niños, niñas y adolescentes. Y debe hacerlo, no solo en base a las necesidades educativas especiales que puedas presentar, en las que la intervención seguirá siendo imprescindible, sino también contemplando todas aquellas situaciones que pueden suponer una situación de desventaja. Y es aquí donde deberá prestarse una atención especial a las medidas necesarias para el reequilibrio territorial, ligando éstas no solo a la transformación y desarrollo de las ciudades, sino también a la calidad de vida de la ciudadanía y a la equidad social.

\section{Referencias bibliográficas}

Ayuntamiento de Madrid (2018). Metodología para la elaboración del Índice de Vulnerabilidad Territorial para los barrios y distritos de la Ciudad de Madrid. Informes y Estudios 2018. Área de Coordinación Territorial y Cooperación Público Social (en línea). https://www.madrid.es/UnidadWeb/Contenidos/Publicaciones/TemaServiciosSociales/IndiceVulnerabil/indicevulnerabilidad.pdf.

Ayuntamiento de Madrid (2020). Informe del Estudio sobre el impacto de la situación de confinamiento en la población de la ciudad de Madrid, tras la declaración del estado de alarma por la pandemia COVID-19. Impacto económico y laboral sobre los hogares. Dirección General de Innovación y Estrategia Social. Área de Gobierno de Familias, Igualdad y Bienestar Social (en línea). https://diario.madrid.es/wp-content/uploads/2020/05/Informe-Encuesta-Impacto-Confinamiento-Ciudad-de-Madrid.pdf

Cabero, J, (2004). Reflexiones sobre la brecha digital. En F. Soto, J. Rodríguez (coords), Tecnología, educación y diversidad: retos y realidades de la inclusión digital (pp. 23-42). Murcia: Consejería de Educación y Cultura.

Prets, C. (2008). Informe sobre la alfabetización de los medios de comunicación en un mundo digital. Comisión de Cultura y Educación. Parlamento Europeo.

Comunidad de Madrid. Atención Educativa a las Necesidades Educativas Especiales (en línea). https://www.comunidad.madrid/ servicios/educacion/necesidades-educativas-especiales, acceso 17 de mayo de 2020. 
Nacional de Estadística (2019). Encuesta sobre Equipamiento y Uso de Tecnologías de Información y Comunicación en los hogares. Año 2019.

OECD Information Technology Outlook 2002. Perspectives des technologies de l'information de l'OCDE : Les TIC et l'économie de l'information. Édition 2002.

Save The Children (2020). Informe A tu lado. Lo que nos cuentan las familias (en línea). https://www.savethechildren.es/sites/ default/files/202003/informesavethechildrenatulado.pdf

UNESCO (2005). Informe de seguimiento de la educación para todos. París: UNESCO. 